In a former paper dealing with the cause of Leber's disease, I pointed out that the pituitary body is known to enlarge to two or three times its normal dimensions in association with pregnancy, and that it fills with a milky juice which can be pressed from it.

The hypophysis is known to be larger in a woman who has borne children than in a nullipara. The explanation in this case seems to me to be that the enlargement of the pituitary body associated with pregnancy exceeded the limits of the normal, and sufficiently so to cause pathological increase of intra-cranial pressure in two successive pregnancies; the enlargement extended particularly to the left side of the sella Turcica, and thus involved the left sixth nerve in the floor of the cavernous sinus groove, and to some extent the left optic tract.

The X-ray picture reveals a sella Turcica of rather unusual depth and with the anterior and posterior clinoid processes closer together than usual. In such a fossa any unusual and rapid swelling of the pituitary body would probably find its path of least resistance to be in the lateral directions, and in this case the swelling gland expanded particularly towards the left side.

\title{
A CASE OF DETACHMENT OF THE RETINA AT THE ORA SERRATA*
}

BY

ARNOLD ' LAWSON. LONDON.

CLINICAL reports of detachment at the ora serrata must be very rare. In my somewhat hasty search through ophthalmic records I have not managed to find a single case and certainly I have never seen one similar to this. As a pathological specimen the condition, though rare, may occur if there is a great shrinkage of inflammatory vitreous exudates, but in such cases the eye must generally be blind before the occurrence, or at any rate so nearly so that a detachment at the ora serrata could not be seen. In the case I am about to relate, the diagnosis was made clinically by ophthalmoscopic examination and subsequently confirmed by pathological investigation.

The patient was a lieutenant of 23 years, who came to see me first at the latter end of October, 1915. He had been wounded at the Dardanelles in the previous May. A bomb burst near him wounding him in the right groin, and almost simultaneously he was struck on the left leg by two bullets, one of which killed his

* A communication to the 1917 meeting of the Ophthalmological Society of the United Kingdom. The full text will appear in the Society's Transactions. 
neighbour on his left. Please observe that he was not to his knowledge wounded in either eye, but he said that his neighbour on the left was shot in the head, and that the head was greatly shattered, and that he was struck and spattered on the left side of his face by fragments of the skull and soft parts, blood, etc.

When he came to me the condition was as follows:-

Right eye. $\mathrm{V} .=6 / 5$ easily. Eye normal in every respect.

Left eye, V. $=6 / 24$ not improved. The pupil was dilated to its widest limits and immobile. There was a slight general vitreous haze with one rather large grey opacity which moved freely.. The condition of the retina and choroid was perfectly normal. The movements of the eye were free and painless; the sclera was quite white; there was no sign of corneal precipitates and the pupil was evenly dilated without notching or any sign of inflammatory adhesions. In fact, the eye was perfectly quiet. Examination of the field showed a slight general and fairly even contraction. Centrally there was a small relative colour scotoma.

I concluded that he was suffering from the effects of a severe concussion. This view was favoured by the history and by the fact that the face on the left side was a good deal bruised at the time he was wounded.

I told him that the length of time that had elapsed since the accident made the prognosis as to recovery of sight rather doubtful, but I thought there was a great probability that he would not get any worse.

He was not much inconvenienced except that he was happier with the left eye covered. This I put down as being in part at any rate due to the mydriasis, and I ordered weak eserin drops (gr. 1 ad $1 \mathrm{oz}$.) to use occasionally.

I saw him two days later and the eserin had answered perfectly, contracting the pupil to its fullest extent, and his vision was improved thereby to 6/12 and letters of 6/9. I might say that I could not get this improvement with a stenopæic disc on the previous visit. He was told to go on using the eserin, the strength of which was reduced to $\mathrm{gr} . \frac{1}{2}$ ad $1 \mathrm{oz}$.

I saw him again about six weeks later. The eserin had been only successful in that it contracted the pupil for a few hours. If not used, the mydriasis became as extreme as it ever had been. The attempt to improve the action of the sphincter by stimulating it had therefore failed entirely. Further, the eserin caused a good deal of temporary aching and confusion of sight after its use. On this account I advised the patient to give it up.

The vision at this date was precisely as before, and the field and ophthalmoscope picture were unchanged.

I next heard of him by a telegram on February 1 saying that he had suddenly lost a great deal of his sight. When I saw him he 
told me that when out walking with a friend he felt the sight of his left eye become suddenly worse, so that about three-quarters of the whole field disappeared and he could only distinguish objects placed high above the horizontal level. When he got home he noticed that the pupil, which was widely dilated as usual on starting out, had become much smaller.

On examination I found the pupil equal in size to the other and reacting both directly and consensually, though not normally so. The eye was rather photophobic and flushed, and the vision reduced to hand movements. I dilated the pupil, and an extraordinary picture was revealed. A fine lace-like veiling, which focussing showed to be the retina, was hanging detached over the lower twothirds of the picture, leaving a gap above it through which the choroid and its vessels were easily. and plainly seen. The upper margin of the detachment went straight across the field and was quite close to the lens and uniform in outline and sharply marked without apparent rent or fold. I concluded that it must be a detachment very close to the ora serrata, and ordered him to bed in a nursing home. At the same time, seeing that the picture was so strange and unusual, I asked Mr. E. Treacher Collins to see the case with me. The occurrence of this detachment and the consecutive change in the pupil made me suspect that there was, after all, a foreign body in the globe somewhere about the ciliary region, the irritation of which had induced the pupil changes and which, in some way difficult to explain, had brought about the detachment. Consequently, after a few days' rest in bed, during which time all the photophobic and inflammatory symptoms disappeared, I asked Sir J. Mackenzie Davidson to skiagraph the eye. This he did and found a minute foreign body localized in the neighbourhood of the ciliary body on the outer side. I decided that, considering all the circumstances, there was nothing to be gained by attempting to remove it.

After a short stay in the nursing home, during which time the upper field became defective also, I sent him home to rest quietly for a time. When at home the lower visual field became much better, so that he could once more distinguish large objects below the horizontal line, but the upper field remained very bad.

When seen again about four weeks after leaving the nursing home I found that the retina to a large extent had apparently reattached itself above, and I could for the first time make out a small shining foreign body high up on the outer side and just within range of ophthalmoscopic examination.

The eye soon afterwards began to show signs of disorganization and became very irritable, the tension became markedly raised and the iris became more and more discoloured, which I thought was probably due to siderosis. The eye was also painful at times, 
and, all things. considered, I strongly advised him to submit to enucleation, which was performed about three months after the first appearance of the detachment. I may add that the foreign body disappeared from view shortly before I removed the eye. It apparently shifted up with the retina in which it was entangled.

\section{Pathological Report by Mr. E. Treacher Collins}

Eyeball received from Mr. Arnold Lawson. It had evidently been in spirit, as the cornea was opaque. It was transferred to a 4 per cent. formalin solution and afterwards frozen and divided by an antero-posterior vertical section. The cornea, besides being opaque, was somewhat wrinkled, due to hardening reagents. The lens was opaque, due to the same cause. The anterior chamber was filled with a gelatinous coagulum. The lens was rounder in shape than normal and displaced slightly upwards. The retina was detached and formed a much puckered membrane lying in the centre of the eyeball. There was hardly any vitreous chamber left, only a small area posteriorly, The space between the retina and choroid was completely filled with a grey coagulum of gelatinous consistency. After this had been removed from the outer half of the globe, the retina at the ora serrata, together with a portion of the pars ciliaris retinæ, was found to be torn away from the ciliary body, both above and below. The only portion of the retina in the region of the ora serrata which retained its attachment was on the outer side of the globe. The whole circle of the pars ciliaris retinæ, together with the suspensory ligament of the lens, had become drawn towards the centre of the globe and to its outer side. At the outer and upper part of the globe a conical projection was seen to pass from the outer surface of the detached and puckered retina, and pass backwards to become adherent to the choroid a little in front of the equator. At the spot where the retina was adherent to the choroid there was a circular area of choroidal atrophy. Behind the lens, at its lower margin, between it and the detached pars ciliaris retinæ, a small foreign body was found, which on being touched crumbled into two. It was attracted by a magnet.

The spot of choroidal atrophy in the upper and outer part of the globe, to which the retina was adherent, was evidently the point of entrance of the foreign body. It must have passed through the vitreous behind the lens to the ciliary region on the opposite side of the globe. The contraction caused in the anterior part of the vitreous, in the track of the wound, was the probable cause of the dragging inwards towards the centre of the globe of the hinder portion of the pars ciliaris retinæ and the retina in the region of the ora serrata. 